\title{
NIÑOS DE LA CALLE: BUENOS AIRES SXXI
}

\section{STREET CHILDREN: BUENOS AIRES SXXI}

\author{
María Verónica Brasesco \\ Investigadora del Observatorio de Drogas del Ministerio de Asuntos Sociales del Gobierno de la Ciudad \\ Autónoma de Buenos Aires, Argentina
}

\begin{abstract}
Resumen: El estudio afronta la problemática del estatus de la infancia y la adolescencia contemporánea considerando especialmente el fenómeno del consumo de sustancias en niños de calle en la Ciudad de Buenos Aires. Se sustenta en una investigación realizada por la autora en el el Observatorio de Drogas GCABA: "Consumo de sustancias en niños de calle”. El objetivo del estudio de caràcter cualitativo se basa en datos recogidos en cincuenta entrevista a niños de calle sobre el consumo de drogas, su funcionalidad y la valoraciòn que los niños hacen del mismo.
\end{abstract}

Palabras clave: niños de calle, evaluación psicológica, consumo drogas.

\begin{abstract}
This study addresses the status of contemporary childhood and adolescence, and in particular the phenomenon of substance use among street children in the City of Buenos Aires. It is based on an investigation by the author in the Drug Observatory GCABA: "Consumption of substances in Street Children”. This qualitative study is based on data collected from interviews to fifty street children on drug use, drug use function, and perception..
\end{abstract}

Keywords: Street children, psychological assessment, drug use.

\section{LA INFANCIA: APRECIACIONES CONCEPTUALES}

El concepto de infancia se inscribe etimológicamente en una dimensión de fragilidad. Infancia provine de in-fari, que no puede hablar, significado que alude a una infancia hablada y legitimada por otros, explicada y descifrada por adultos, sin los cuales el niño no podría existir. El origen de la palabra conduce al niño al enmudecimiento, pasible de ser expresado sólo a través de discursos que no le pertenecen.

También el niño se asocia a una figura débil, inmadura desde el punto de vista biológico, inexperimentada y torpe, en oposición a los significados otorgados a la figura del adulto. Es decir, la infancia se concibe como una zona de inexpresión, no-memoria e incapacidad en sentido general.

Hasta hace pocos años se consideraba que la niñez, desde el punto de vista psicológico, abarcaba el período entre el nacimiento y la edad adulta, en el marco de un proceso continuo de marcha hacia un estado de mayor equilibrio orgánico, afectivo, intelectual y social.
Hoy existe consenso en considerar la niñez mucho más que el tiempo que transcurre entre el nacimiento y la edad adulta. Se trata de un estado y condición de la vida del niño que comprende una especificidad en la calidad de esos años vividos. Dicha calidad de vida se asocia a innumerables factores, tales como la consideración o el tratamiento que los niños reciben en la familia, en la comunidad y en la legislación, así como también a las clases sociales de pertenencia, la valoración socio cultural de la niñez, los avatares sociales, económicos y políticos y el abordaje de la infancia que se realiza desde las diferentes disciplinas entre otros.

Esta visión necesita de niños y niñas activos y capaces de autorreflexión acerca de su propia condición de vida, y de ciudadanía capaz de preguntarse y someter a crítica aquello que se piensa acerca de la infancia, de las actitudes que se derivan de dicha visión de los niños y de la necesidad de proteger sus derechos y generar un mundo apropiado en un espacio protegido para que éstos puedan crecer, jugar y desarrollarse: el desarrollo de la experiencia más importante del niño, su infancia, depende 
en gran parte del cuidado y la protección que recibe de los todos aquellos que tienen alguna obligación para con la infancia -gobiernos, organizaciones internacionales, la sociedad civil, las familias y los individuos.

\section{DESARROLLO HISTÓRICO DEL CONCEPTO DE INFANCIA}

Históricamente la infancia ha tenido diversos enfoques en su definición y descripción ya que como concepto, es simplemente una categoría estructurada por el hombre que puede ser extendida o prolongada en algunos períodos o abreviada en otros, según la apreciación de los adultos, sus necesidades y expectativas.

La Infancia ha sido también tema de interés de historiadores europeos, quienes amparados en un profundo conocimiento de la historia social de dicho continente, han enunciado una evolución universal 'del ser niño' desconociendo la historia y el desarrollo social de culturas de otros continentes. Europa exportó estos modelos propios explicativos de problemáticas asociadas a la infancia, inicialmente adoptados en el llamado Tercer Mundo, pero que fueron mostrando paulatinamente carencias e inadecuaciones para comprender la compleja realidad local de la infancia.

De acuerdo con los resultados de sus investigaciones en el campo de la Historia del Arte, el historiador francés Philippe Ariès observó, a través de un lente europeo contemporáneo, que antes de la Modernidad no se definía a la infancia con los rasgos que actualmente se consideran prototípicos de este período como la inocencia, irracionalidad, predominante interés por el juego, etc. Finalmente, el autor concluye que la infancia no existió en Europa hasta el siglo XIV en los términos y características que hoy se le adjudican. Al respecto Ariès (1988) sostiene en que hasta el siglo XVII, el arte medieval no trataba de representarse la infancia porque en esa sociedad no había espacio para la infancia.

Ariés relata cómo los niños, incluidos en la vida de los adultos desde muy pequeños, eran considerados pares en cuanto fuerza de trabajo, atención de bebés y enfermos y ocupaciones asociadas al trabajo doméstico en general. Indica que en Europa hasta el S XIV, los niños parecían no tener un lugar específico que les diera identidad, ni un contorno social que los diferenciara claramente de los adolescentes y de los adultos.
Antes de la Modernidad los niños pequeños compartían con niños mayores y adolescentes tanto aulas escolares como tareas rurales, hecho que según el autor, actualmente no se verifica en el continente europeo porque los niños no trabajan y no existen más aulas integradas pobladas con niños de diferentes edades. La Convención de los Derechos del Niño (1988), citando los "cuidados y asistencia especiales" que necesitan los niños y las niñas deja definitivamente atrás esta concepción de vida adultomórfica y, por el contrario, reconoce que lo que resulta apropiado para los adultos puede no ser adecuado para los niños.

A este punto se puede decir que no existe la niñez, sino que la palabra alude a lo que cada cultura y cada grupo social en diversos momentos históricos definen, representa e interpreta como niño haciendo referencia a valores comunes desarrollados en cada uno de los grupos humanos. Los particulares modelos educativos, la validación de diferentes formas de aprender, los tiempos y significados otorgados a fenómenos evolutivos están asociados al ambiente sociocultural y geográfico en el cual el niño se desarrolla.

Podemos afirmar entonces que el discurso abstracto de la niñez, se ocultan niñeces concretas, histórico-social y políticamente muy diferentes. Cada niño que nace se sitúa en un crisol de opiniones, creencias, estilos educativos y expectativas que lo ubican en un ser niño acorde con las representaciones e imágines de la infancia de un grupo social dentro de una determinada cultura. Especificidades en las estructuras de parentesco, en el desarrollo de los afectos, en los regímenes político económicos generan trayectorias complejas de experiencia de vida y resultan determinantes en la construcción de la identidad de los niños.

La reflexión sobre la actualidad de la infancia en Argentina, convoca a considerar entonces, la existencia de niños que viven en condiciones económicas y socio-culturales muy distintas en un mismo territorio y en un mismo momento, a diferencia de las formas secuenciales de ser niño que describen los autores en la historia de Europa, incluyendo en vez el análisis de representaciones sociales sobre la infancia vigentes en poblaciones culturalmente heterogéneas.

Hoy en Argentina hay niños indígenas, inmigrantes, gitanos, trabajadores, niños de barrios privados, niños amparados y acompañados en el desarrollo de sus potencialidades y niños de 
la calle que no son sujetos plenos de derecho. Esta contemporaneidad de infancias tan disímiles en nuestro territorio, indica a la vez potencialidad futura y tensiones y contradicciones en la vida social, en las familias, en la escolarización y en los espacios de juego, tantas veces inexistentes en la vida de los niños.

No se trata infancias figuradas sino de niños de carne y hueso que nos impelen a dar una respuesta con acciones sustentadas en conocimientos y políticas adecuados a los nuevos problemas emergentes en este complejo escenario social.

\section{LA NIÑEZ INVISIBLE EN LAS METRÓPOLIS LATINOAMERICANAS}

Entre 1930 y 1980, se dio en Latinoamérica un rápido proceso de urbanización que llegó a un 65\% (UNPD, 2002). Este proceso, sin embargo, ocurrió de manera totalmente desigual: las ciudades más importantes (en general las ciudades capitales) tuvieron un crecimiento sobreproporcional, siendo su pronunciada posición de predominio demográfico el resultado de la centralización del desarrollo económico.

En el marco de este fenómeno del incremento de la marginalidad y expulsión infanto - juvenil a espacios públicos y a una vida sin proyectualidad donde se verifica la existencia de niños/as en situación de calle sin hogares o con hogares donde los vínculos parentales van al encuentro de una progresiva desintegración. El consumo de sustancias, acompaña en esta instancia la cotidianeidad de los niños en cada uno de sus momentos.

Cada día son más los niños/as que llegan a los hospitales con graves daños neurológicos y otros problemas de salud de severa entidad por el uso de paco, inhalantes (colas, solventes y naftas) y otras sustancias psicoactivas. En cuanto al paco, a diferencia del Clorhidrato de Cocaína para cuya elaboración se necesita un laboratorio con cierta complejidad en la infraestructura, esta droga es de elaboración casera. Se trata de una sustancia altamente adictiva y la persistencia en su consumo puede causar trastornos irreparables en la salud y en algunos casos, por dosis elevadas, la muerte. De acuerdo con los precursores químicos que se utilicen el color varía entre amarillento o amarronado, se fuma en pipas hechas generalmente con caños de aluminio de antenas de televisión o guías de cortinas. Los niños llegan a fumar entre 10 y 15 "pacos" en un día, número que en combinación con alcohol puede ascender a 50 o 60 o más en un solo día.

De acuerdo a los estudios realizados por el Observatorio del Gobierno de la Ciudad Autónoma de Buenos Aires en los Hospitales Generales de la Ciudad, en una semana llegaron a la guardia médica de estos hospitales 10 menores de edad en estado de intoxicación aguda, con variados niveles de alteración de la conciencia y riesgo de vida.

\section{LOS NIÑOS Y NIÑAS DE LA CALLE}

El niño/a en situación de calle se caracteriza por la inestabilidad de las relaciones afectivas con el mundo de los adultos que deriva en una identificación insuficiente con modelos de adultos estables. La ausencia de referencias estables, donde toda relación puede ser súbitamente perturbada por un acontecimiento imprevisto y súbito que los obliga a estar en constante movimiento con el fin de protegerse, los lleva a desarrollar un agudo sentido de la observación (Lucchini, 1996).

Asumen constantemente el presente con gran esfuerzo psíquico y afectivo, en el marco de las relaciones sociales inestables y discontinuas donde el consumo de droga deviene en un medio más, utilizado para afrontar problemas de adaptación social, al medioambiente y de sobrevivencia psíquica. La miseria, el grado de abandono y las carencias en el plano de la salud, de la formación escolar y de la familia, hacen que la lucha por la supervivencia sea un problema permanente. Se trata, en primer lugar, de la supervivencia física, psíquica y social.

Estando en constante movimiento con el fin de protegerse, saben reconocer con facilidad signos de peligro o de facilitación vinculados con la supervivencia en la calle que guían en forma aislada las conductas. Esta circunstancia condiciona el aprendizaje de las normas perceptivas, de evaluación y de comportamiento que organizan las relaciones con el entorno y que van configurando la identidad.

Si bien esta población se presenta en un proceso continuo y gradual de transición respecto a las diversas situaciones de vivencia de calle y a todos se los reconoce con la denominación niños/as en situación de calle, se pueden distinguir dos grupos: los "niños/as y adolescentes 
en la calle y niños/as y adolescentes de la calle. Se reconoce a los niños/as de la calle como un grupo extremadamente vulnerable y alto nivel de complejidad psicosocial, vínculos familiares escasos o nulos, estrategias de supervivencia que comprometen gravemente el ejercicio de los derechos del niño (mendicidad, robo, explotación y comercio sexual) que dificultan el acceso y permanencia en el sistema escolar y facilita la cronificación en el consumo de drogas.

El grupo de chicos en la calle se caracteriza por ser muy heterogéneo, donde el grado de vulnerabilidad depende del tiempo de permanencia en la calle, la complejidad de las problemáticas familiares, la situación de integración escolar, los niveles de consumo de drogas, la inclusión y magnitud de actividades delictivas como infracciones o faltas menores, o estar en infracción por haber cometido delitos.

Sintetizando, desde el punto de vista de esta caracterización, los niños/as de la calle se encuentran en un estado de abandono total, no tienen adultos significativos de referencia para la toma de decisiones cotidianas y su supervivencia y viven en la calle permanentemente. Los niños/as en la calle, en líneas generales retornan asiduamente a hogares y tienen adultos significativos que guían y/o determinan las estrategias de supervivencia, en un contexto de conflictividad en el seno de la vida familiar.

Ambos grupos forman parte de la población de niños/as en calle, cuyas actividades cotidianas comprenden mayor o menor riesgo personal de acuerdo a si las realiza solos o con la familia. En estos niños no se satisfacen las necesidades básicas, por el contrario, se vulneran en forma sistemática los derechos de la persona, no cumpliéndose por ende los requisitos indispensables para el desarrollo integral de la infancia y la adolescencia.

En la Ciudad Autónoma de Buenos Aires, la Dirección General de Niñez y Adolescencia realizó en enero de 2008, un censo de niños/as y adolescentes en las calles de la CABA donde se incluyeron, entre otras, preguntas específicas sobre consumo de sustancias en población de calle y datos afines. Los niños/as y adolescentes fueron abordados por los primeros dispositivos del circuito de atención en calle como el Equipo Móvil, CAINA y dispositivos de tránsito: Paradores y ONGs.

Entre los datos más relevantes surge que sólo el $21 \%$ de los niños nació en la CABA. Los niños del Gran Bs. As. tienen más hermanos en calle que los originarios de la ciudad. En líneas generales paran/ranchan con pares, ya que solo el $27 \%$ para con adultos y/o familia. Algo más del $30 \%$ de las niñas estuvo embarazada alguna vez, la mitad de las cuales tuvo un hijo. Un tercio de los niños se fue de la casa por conflictos familiares y un cuarto por maltrato físico o abuso sexual.

El tiempo medio de residencia en la calle es de un año y el $50 \%$ de los niños/as mantiene contacto con su familia, que va disminuyendo paulatinamente a medida que aumenta la edad de los entrevistados. Del total de niños/as y adolescentes entrevistados, el $75 \%$ no asiste a la escuela, prevalencia que aumenta en los mayores de 13 años. Menos del 20\% completó los estudios primarios siendo la proporción de quienes no asisten a la escuela mayor entre quienes viven en la Provincia de Buenos Aires que entre aquellos que residen en la CABA.

Más del 75\% consumió algún tipo de drogas, resultando la marihuana la sustancia más consumida, el tolueno la segunda, y en tercer lugar el alcohol. Consumen entre pares, los más pequeños preferentemente de día y los mayores en horarios nocturnos.

\section{INVESTIGANDO EL FENÓMENO}

Realidades humanas complejas ${ }^{1}$ como las de estos niños/as y adolescentes consumidores de Paco y otras drogas, exigió la implementación de una metodología de estudio que permitiera la comprensión del fenómeno del consumo en "Poblaciones en vulnerabilidad social" en forma holística, para poder captar los factores sociopolíticos, históricos y económicos.

Aún a sabiendas que NO hay observaciones objetivas sino contextualizadas socialmente y que NO existe un único método a través del cual

\footnotetext{
1 "Complexus quiere decir, lo que está tejido en conjunto: la trama, el tejido de constituyentes heterogéneos inseparablemente asociados que presenta a la vez la paradoja de lo uno y lo múltiple; un tejido de eventos, acciones, interacciones, retroacciones, determinaciones, azares que constituyen nuestro mundo fenoménico." (Morin, 1997, pp. 32).

2 Población en vulnerabilidad social es una expresión que hace referencia a una población heterogénea, en la que se observan distintos grados de complejidad/vulnerabilidad psicosocial. Los programas de prevención selectiva que intervienen en el ámbito psicosocial están enfocados a la población de mediana y alta complejidad, que corresponde a la llamada población en situación de calle, a la que generalmente no llegan, ni se ve influida por otros programas preventivos comunitarios o escolares.
} 
podamos alcanzar y comprender totalmente las sutiles variaciones de la experiencia humana, se decidió implementar metodologías cualitativas de investigación que dieran cuenta de:

- La particularidad del fenómeno a indagar (patrones socioculturales que sustentan las prácticas de consumo a fin de comprenderlas en su especificidad y particularidades en grupos vulnerables).

- Las características del contexto de vida cotidiana intentando comprender el sentido de los fenómenos de acuerdo con los significados que tenían para las personas implicadas.

- Las iniciativas, experiencias y las expresiones subjetivas y los significados dados por los propios sujetos estudiados en estos particulares grupos de población.

- Las percepciones de los actores del fenómeno del consumo desde adentro y las formas en que narran, actúan y manejan sus situaciones cotidianas.

La técnica cualitativa para la recolección de datos fue la Entrevista en Profundidad.

Se realizó un estudio de carácter etnográfico transversal descriptivo con informantes claves de carácter cualitativo que comprende la indagación de los significados del consumo de Paco y otras drogas desde la perspectiva de los actores: niños/as y adolescentes en situación de calle con los siguientes objetivos:

\section{General:}

Definir el perfil de consumo de sustancias psicoactivas en niños y niñas de calle, sus significados y funcionalidad.

\section{Específicos:}

- Caracterizar, teniendo en cuenta el contexto social y cultural específico, el tipo de modalidad de consumo de sustancias en general y de Paco en particular.

- Individuar las funciones del consumo en las estrategias de vida del niño de la calle.

- Describir y comprender las representaciones sociales e individuales, así como el sentido que el niño da a este consumo.
El instrumento utilizado para el registro de datos fue un guión de entrevista en profundidad que permitió estudiar el fenómeno del consumo de sustancias, representaciones, significados y vivencias en niños/as y adolescentes que aún se encuentran haciendo vida de calle.

\section{Las dimensiones de análisis del fenómeno}

- La calle como ámbito de vida

- Las bandas de niños/as y de adolescentes y su subcultura

- La socialización del niño en la calle

- Los procesos de crecimiento

- Los desplazamientos del niño en la ciudad

- Relatos e historias biográficos

- El acceso a la droga y las modalidades de consumo

- Utilización de niños/as en el tráfico de drogas

- Drogas utilizadas y frecuencia de consumo

- Funciones de la droga en el grupo de niños/as

- Iniciación en el consumo de la droga y situaciones típicas de consumo

- Utilización del alcohol

- Significados y vivencias del consumo

- El valor de las instituciones (paradores, hogares, instituciones de salud, etc.)

- Futura, expectativas y proyectos.

El trabajo de Campo comprendió 50 entrevistas en profundidad a niños/as en situación de calle, varones y mujeres de 8 a 15 años de edad, estando a cargo del relevamiento un grupo de profesionales apósitamente capacitado en la metodología. El trabajo de campo fue realizado en el curso de treinta días en Hogares, calles y plazas de la Ciudad de Buenos Aires.

El estudio fue realizado en el marco del Observatorio de la Dirección de Adicciones del Gobierno de la CABA y no tuvo como propósito dar respuesta exhaustiva a todas las problemáticas de este grupo población, sino aportar datos sobre las dimensiones establecidas de modo tal de producir información tendiente a circunscribir la problemática, para efectuar adecuadas intervenciones por parte del Estado y la sociedad civil.

Aún sabiendo que si no se verifica un cambio en las condiciones de vida de estos niños/as y adolescentes, el consumo continuará siendo una actividad importante en sus vidas, este 
estudio buscó explorar el contexto en el que se da el consumo, incluyendo las representaciones del niño sobre sí mismo y el mundo y las relaciones con el medio (control social, socialización y adquisición de estatus social, circunstancias que condicionan las vicisitudes del consumo de sustancias y la percepción subjetiva y vivencias de las mismas).

\section{LOS DATOS}

Existe tolerancia social hacia el consumo de sustancias en gran parte de las familias de origen de los niños ("Mi papá y mi mamá toman cerveza, pero está mi hermano que fuma porro, toma merca, se empastilla, jala, después está el otro el rubiecito que fuma porro, jala, toma pastilla, toma merca, todo"; "Mi hermano Lautaro es mellizo mío, se droga con porro, con paco, con poxi, que jala más o menos un kilo"; "Con papá que se llama Cacho y que me trata bien no me puede quedar porque tiene un hermano, Juancito de 18 años, que se droga con merca, poxi y porro").

Además de la violencia social que implica la pobreza, donde por familia conviven entre 5 y 12 hermanos hacinados en casillas monolocales, los niños trabajan y mendigan desde muy pequeños sin tener cubiertas las necesidades básicas ("Me fui de casa porque no había ni para leche para mis hermanitos") y abrigo ("No tenemos cocina porque se la robaron").

Cabe destacar también que muchos de estos niños crecen en ambientes donde se ejercen todas las formas de maltrato infantil: sexual, físico ("Me peleo con mi mamá porque mi padrastro le pega,... quiere que yo vaya a vivir a la casa, pero yo no me lo banco"; "Mi mamá me pega a mí y a mis hermanas porque se emborracha") y psicológico ("No se llevan bien conmigo, discuten porque no quieren que esté ahí con ellos").

Otros niños van a vivir a la calle después de haber ingresado en el circuito judicial, ya que al salir de los institutos ya no vuelven con la familia sino que son derivados a hogares residenciales o se reúnen en las ranchadas con otros niños y adolescentes que conocen en dichas instituciones ("Lo que pasa es que mi hermano robó y la policía nos trajo a los dos a Niñez y después nos llevaron al hogar").

Los niños que se encuentran institucionalizados, pierden progresivamente el sentido de pertenencia con el grupo familiar ("Voy a la casa de mi tía en Bajo Flores los fines de semana. Estoy desde los 12 con un hermano más chico en el hogar... hace casi tres años... entro y salgo todo el tiempo, a veces voy a lo de mi tía $y$ a veces me quedo en la calle").

Casi todos los niños han tenido algún momento de pasaje por las instituciones escolares. Sólo en dos casos se verificó la falta absoluta de escolarización de los niños con el consecuente analfabetismo y la instrumentación de estrategias singulares para la comprensión global de la señalética y mensajes escritos.

Los motivos por los cuales los niños dejan la escuela prevalentemente entre el $2^{\circ}$ y $7^{\circ}$ grado son variados. Entre los más frecuentes se describen situaciones familiares signadas por la pobreza y la necesidad de subsistencia del grupo, que sustentaron la decisión de los adultos o de los niños a salir a trabajar o mendigar ("Fui hasta $5^{\circ}$ grado... Dejé porque que tenía juntar plata para ayudar en casa. Me gustaría volver a la escuela"; "Hice hasta $4^{\circ}$ grado, cuando estaba por pasar a $5^{\circ}$ me borraron de la escuela porque faltaba mucho para terminar y entonces me mandaron a pedir plata a la estación de Once"; "Llegó hasta $3^{\circ}$ y abandoné porque no iba casi nunca porque tenía que ir a la estación todos los días a pedir plata para pañales y leche para mis hermanos").

En otros casos el abandono escolar coincide con el abandono del hogar por causas dolorosas y/o complejas como maltrato físico ("Llegué a $7^{\circ}$ pero no terminé... en la 46 de Lanús. Me gustaba la escuela... me iba bien... me gustaba inglés y matemáticas... No terminé la escuela porque me tuve que ir de casa porque estaba todo mal, me cagaban a palos"), desgracias familiares ("Justo en ese año había fallecido mi viejo y me agarró el bajón de dejar todo: irme de mi casa, dejar el colegio, no estudiar, vagabundear todo el día"; "Fui a la escuela hasta $3^{\circ}$ en José C. Paz. Se murió toda mi familia en un accidente del tren.... después me fui al Parador Perla Negra") o embarazo ("Me gustaba ir al colegio. Dejé de ir porque quedé embarazada y me tuvieron que internar porque tuve problemas con el embarazo").

Muchos abandonos son motivados por desinteligencias de las instituciones escolares en el manejo de los problemas de conducta de los niños ("Dejé en $3^{\circ}$ porque mamá me sacaba a cada rato porque se peleaba con los maestros porque yo me portaba mal"; "Fui hasta $7^{\circ}$ y me 
expulsaron porque hacía mucho quilombo y me drogaba siempre antes de entrar"; "Fui hasta 10, me fue bien y me felicitaron y pasé a $2^{\circ}$, pero me peleaba con los compañeros y me echaron de la escuela por hacer quilombo"; "Hice 10, me gustaba matemática y a, e, i, o, u... con la maestra me llevaba bien... Dejé porque robé en la escuela").

Una vez en la calle, los niños pasan y se mueven dentro de áreas territoriales circunscriptas donde conocen los lugares para procurar comida, asearse, jugar ("Paso mucho tiempo del día en el cyber jugando con amigos en red"), hacer changas ("Me despierto y a la mañana pido plata y limpio foquitos de los autos. Después como al mediodía... a la tarde sigue pidiendo y limpiando foquitos. A la noche como y duermo en la ranchada. A veces pido solo y otras con un amigo, cerca de la avenida 9 de Julio... ando por Lavalle y la avenida 9 de Julio"), y donde comprar drogas y donde consumirla ("Me levanto tarde, a eso de las 6 de la tarde, como, fumo pasta y salgo a robar... ando por la zona de los Barrios Rivadavia 1 y la Villa 1-11-14").

Luego de aproximadamente un año de vida en la calle presentan un notable conocimiento de la oferta de servicios de los paradores de la Ciudad de Bs. As. y del Gran Buenos Aires ("Llego al Santa Catalina a eso de las 9, me baño, almuerzo y voy a los talleres de música, pintura y Karate"; "A la mañana voy al CAINA, y a la tarde al Santa Catalina, como, juego, me baño, miro tele, hago deportes, y voy a Puentes escolares que me encanta"). Especialmente las niñas hacen uso de los paradores para higienizarse diariamente $y$, aquellas que son madres, reciben en estas instituciones leche y pañales para sus bebés. Algunos niños llevan siempre consigo un bolsito con elementos de higiene personal para asearse en los paradores o en las estaciones de servicio.

En relación a los modos para procurar alimentos los niños piden comida a la salida de las hamburgueserías, las panaderías, kioscos y los bares, o bien procuran el dinero a través de labores tales como malabares, limpiar parabrisas, limpiar autos, abrir puertas de taxi, cuidar coches vender diarios, ayudar a los mozos a ordenar las sillas, y las mesas cuando cierran los locales o ayudando a cocinar ("Hace un tiempo estuve trabajando en una pizzería como ayudante de un pizzero, 4 meses y medio. Dejé porque estaba muy cansado, eran muchas horas, pero era bueno porque tenía mi plata y comía ahí"). También venden lapiceras y otros objetos en el centro de la ciudad y sacan monedas de las fuentes ("Para conseguir plata también voy a Palermo y saco monedas de la fuente, a veces saco hasta $\$ 70, \$ 80$ en un día, y los cambio por billetes para no perder las monedas").

Paradojalmente la supervivencia de los niños de la calle en la ciudad, depende del movimiento comercial y financiero de la City; es decir, son marginados por el sistema que maneja la economía de las grandes urbes, pero viven de los despojos de los ciudadanos que circulan en estas áreas. Cuando durante los fines de semana se detiene el movimiento comercial y financiero en el micro centro y cierran los locales de comida rápida y otros negocios, los niños deben desplazarse hacia otras zonas de la ciudad para procurarse alimento o ir de visita a casas de familiares y conocidos, quedando 'stand by' hasta que la City vuelve a despertar los lunes por la mañana ("Paro en el Parque Lezama, también en un puente que hay cerca de ahí, y también en el Mc Donald's que está en frente del Parque, también duermo ahí. Los fines de semana es distinto porque el Mc Donal's está cerrado, entonces hay que ir a otros lados a pedir plata y comida... los fines de semana duermo todo el día).

El tren y las estaciones constituyen un área ciudadana fundamental dentro del hábitat de estos niños, ya que poseen una multifuncionalidad de casa/barrio/medio de transporte/lugar de trabajo/lugar de juego y recreación ("Los fines de semana voy a Laferrere a bailar hip hop con amigos en la estación de tren... Todos los días paso mucho tiempo arriba del tren yendo de Once a Moreno").

Niños y niñas perciben a los paradores y hogares como lugares de anclaje transitorio donde reciben afecto que cortan las jornadas vacías deambulando por la ciudad sin referencia de tiempo ni espacio ("A veces no me doy cuenta qué día es, si es de semana o de fin de semana...Me levanto a cualquier hora y voy a la plaza o a caminar. Camino por todos lados, ando en subte... algunos me dejan pasar y otros no y paso por abajo. Lo que más me gusta es el Santa Catalina porque me tratan con cariño, me tratan bien").

Solo unos pocos niños tienen muy claro la diferencia entre días de semana y fines de semana, así como la división de los horarios 
durante el día y las funciones que se cumplen en dichos horarios. Estos niños en situación de calle vienen por determinadas horas a realizar actividades al centro (cartonear, mendigar, etc.) y retornan todas las noches a su hogar a dormir ("Actualmente vengo todos los días.... lunes a viernes desde las 3 más o menos hasta las 8 de la tarde... pido monedas en la estación Once. Ando siempre con mi hermano").

En los hogares y paradores los niños suelen crear fuertes vínculos con los operadores que van más allá de los momentos que se comparten dentro de los muros de la institución ("Ando por San Telmo o Constitución. A veces no hago nada y me voy a la casa de mi amigo que vive en Barracas y lo con la mensajería. Mi amigo es grande, se llama M., es el profesor del Santa Catalina y ayuda a todos los pibes de la calle").

Mientras los niños son pequeños a través de la mendicidad aseguran la propia subsistencia, pero a medida que crecen el ingreso de dinero y la comida obtenida por este canal disminuye y comienzan a participar asiduamente de actividades delictivas (por lo general se trata de rapiñas oportunistas ${ }^{3}$ ) para cubrir sus gastos básicos y actividades recreativas tales como frecuentar los locales de cyber.

El miedo es el sentimiento habitual que acompaña a los niños en la calle y, dentro de las estrategias para conseguir sentirse amparados, se agrupan. Dentro del grupo se encuentran otros niños que consiguen comida o los defienden ante las agresiones físicas de otros niños o adultos. De la policía no esperan protección ni cuidados, solo desean no tener problemas con ellos y que no los molesten ("Los chicos de la redonda me cuidaban..."; "Los chicos quieren mucho a mi bebé, me ayudan entre todos porque están en la misma situación. Con la policía no tuve problemas"; "Cuando duermo en la calle tengo una ranchada fija en el Abasto. Ahí tengo amigos, colchón y frazada. Los chicos son más grandes y me protegen").

Cuando se arma un grupo, el niño se reconoce como parte de tal y responde a las solicitudes de sus compañeros sin demasiados miramientos ni preguntas acerca de los fines de las acciones ni las consecuencias posibles ("Ayudé a un amigo a robar una moto y por eso me hicieron un expediente en el juzgado de menores"). Los motivos por los cuales se admiten

3 Uno solo de los niños entrevistados estaba armado y dijo utilizar el arma para robar. los niños nuevos en el grupo son inciertos. En el caso en que el grupo decida rechazarlo es probable que el niño sea corrido con una fuerte golpiza ("Dormimos juntos, consumimos juntos, todos juntamos lo que conseguimos para comprar drogas... antes éramos como 16 y ahora cualquier gil viene y lo dejamos... le pegamos a muchos guachos allá en el Tigre; a uno, un tal Carlitos le dí una patada acá en el tabique").

Cuando los niños se quedan a vivir varios meses en las instituciones arman nuevos grupos de referencia entre los niños con los cuales conviven ("Hoy mis amigos son los del parador, el profesor de Santa Catalina y el chico del taller de moto... no sé cuántos años tiene"). Otros en vez, al dejar la vida de calle se aíslan dentro de las instituciones y sienten una cierta nostalgia por la vida libre ("En la calle me empecé a juntar con chicos más grandes. Desde chico empecé a robar con amigos. Robé casas y un banco con amigos más grandes como de 40 años. Con mis amigos nos peleábamos con otra banda de chicos. Desde que estoy en el hogar, estoy solo").

La vida con el grupo de pares por lo general resulta satisfactoria. Los argumentos que esgrimen para sostener las bondades en la vida en calle se asocian preferentemente a la autodeterminación y el ejercicio casi absoluto de la libertad de indicaciones de mayores y/o de reglas institucionales (En la calle no te tenés que bancar a tus padres y nadie te molesta"; "Lo que más me gusta de vivir en la calle es la libertad, que nadie te diga lo que tiene que hacer").

El consumo de drogas legales (alcohol y tabaco) constituye un hábito arraigado en la mayoría de los niños que viven en situación de calle, que se instala entre los 6 y los 14 años. En el consumo de tabaco la mayoría de los niños se inicia cuando comienza a vivir en la calle. Muchos de los niños que viven en calle en las ranchadas junto a sus madres relatan que sufrieron algún tipo de reprimenda cuando comenzaron a fumar ("Tenía 9 años. Mamá me retó mucho cuando me vio fumar", "Mamá me dijo del cáncer. Por eso fumo poquito, porque si no le mando todo el día"). Algunos niños cuentan que comenzaron a fumar cuando estuvieron en instituciones del estado como hogares e institutos ("Ahí todos fuman y también los que trabajan ahí con los chicos fuman todo el día").

Vivir en la ranchada junto a la madre parece ser un factor de protección para el consumo de drogas legales. Los niños relatan serias 
reprimendas y advertencias realizadas por sus madres en relación al consumo de alcohol y tabaco ("En casa no fumo ni tomo porque mi mamá me reta....tomo Alcohol y fumo con los chicos afuera ${ }^{4 \prime)}$.

Los niños se inician en el consumo de alcohol paralelamente al consumo de tabaco (entre los 6 y los 14 años). Muchos relatan que se iniciaron en el consumo de alcohol en situaciones donde los familiares también consumían ("Mi papá me dio plata y yo compré vino con unos chicos que le pidieron a mi papá, y ahí tomé y empecé.... tomo cerveza, vino, frizee... "; "Empecé a tomar con mi hermano"; "Empecé a tomar con mi familia, para las fiestas y también con los amigos").

Otros niños se inician en el consumo de alcohol en las ranchadas y en la calle ("Empezamos en las "chacotas....son como fiestas que hacemos con los amigos, compramos alcohol y bailamos con los chicos del barrio"). Las bebidas que toman son variadas incluyendo cerveza, vino, fernet, licor mariposa, y bebidas cuyos nombres desconocen ("Creo que se llama Fernandino"; "Un trago color rojo que no me acuerdo como se llama").

Son raros los casos de niños de niños de la calle que nunca han consumido sustancias ilegales y dan como razón de su conducta atípica dentro del grupo, motivos tales como haber recibido en algún momento consejo de familiares (“...porque me decía mi hermana que eso te hacía mal a la cabeza y todos dicen te hace mal, te hace mal"), temor o rechazo a las sustancias ("Me da miedo el pegamento"; "el Paco me da asco"). Todos los niños entrevistados recibieron oferta para consumir marihuana o Poxi-ran, y tan sólo dos refirieron que nunca les habían ofrecido Paco.

En la mayoría de los casos las drogas de inicio fueron Poxi-ran y marihuana. La edad de inicio en el consumo de sustancias psicoactivas más temprana, de seis años, se verificó con marihuana ("Lo primero que empecé a consumir fue faso a los 6 años. Estaba con un amigo mío que era amigo de mi papá, él fumaba y un día yo vi arriba de la mesa un faso y me invitó y yo ese día que fumé y estaba re loco, re loco y salí para todos lados a robar; a mí me gustó toda esa movida y yo empecé a fumar, fumar, fumar; después tomé merca, me gustó empecé a tomar ,tomar, tomar") y Poxi-ran ("A los 6 empecé a drogarme con Poxi-ran. Se me ocurrió porque vi a unos pibitos

4 El niño hace referencia que consume fuera de la ranchada donde para con su madre. que estaban con eso y no sabía que los pibitos también fumaban merca").

La mayoría de los niños se inicia con Marihuana. La edad de inicio en el consumo de sustancias psicoactivas oscila entre los seis y los once años, inicio que se verifica en el lugar de residencia -hogar/ranchada, y en algunos casos en la escuela o en los institutos donde se hallaban internados. En todos los casos los proveedores de drogas resultan ser otros niños 0 adolescentes que se encuentran alojados en dichos lugares.

Por lo general el inicio del consumo de drogas ilegales coincide con el abandono más o menos definitivo de la casa de familia o bien con el corte de vivencias familiares estresantes. Los estados emocionales, las percepciones y las conductas que generan estos primeros consumos son variados. Algunos niños se atemorizan al percibir la alteración de los estados de la conciencia ("Al principio no me gustó por el mambo que me agarré, después me asusté porque sentía que el corazón me latía diferente. Sentía todo lento, no sabía si podía leer algo que veía, me levantaba y me caía, estaba muy mal, por ejemplo, escuchaba una voz y se me aparecía en la cabeza, se me repetía dos o tres veces más y yo miraba ahí y quedaba muy colgado mirando, todo el día colgado").

Otros relatan haber sentido en las primeras experiencias de consumo excitación y omnipotencia ("Flashé un montón de cosas al aspirar, tenía menos hambre....el brazo lo tengo enyesado porque tuve que saltar porque venía la policía y yo tenía la bolsa de pegamento..."; "Lo primero fue el porro... el mundo se me movía. Tenía 7 años. Cuando terminé de drogarme agarré el arma que tenía mi hermano y empecé a jugar....era porque estaba drogado"). También hubo quienes sintieron solo malestar ("El poxi me ahogó").

Todos los niños recuerdan el lugar y la edad en la que consumieron la primer droga ("Cuando me drogué me mareé, llegué a mi casa y se lo conté a mi hermana que me pegó fuerte en la cara y ahi me dijo rescatate y me quedé duro y no probé más. Ella piensa que las drogas me hacen mal"), pero en muchos de ellos el recuerdo ya no es nítido a partir de la segunda droga ("A los 11 años probé porro...estaba con mi hermana y otros chicos más chicos que yo. Después empecé a consumir poxi...no me acuerdo cuando fue...no sé cómo conseguí... pero me gustaba más el porro"). 
En relación a la cronología en el consumo de drogas, por lo general en los niños cuya primera droga fue el Poxi-ran, la segunda resulta ser la Marihuana y viceversa. Es decir que a un inicio con Marihuana prevalece el consumo del Poxi-ran como segunda droga. Luego se incorporan las otras drogas ocupando el tercer lugar tanto el Paco como las Pastillas. El Clorhidrato de Cocaína por lo general aparece entre las últimas drogas consumidas. Las drogas que quedan instaladas en el consumo cotidiano de estos niños son prevalentemente la Marihuana y el Poxi-ran.

Los niños refieren haber probado varias drogas, muchas de las cuales resultan sólo una instancia de experimentación. Las drogas que quedan instaladas en el consumo cotidiano de los niños en situación de calle son mayormente la marihuana y el Poxi-ran ("marihuana hay siempre, es lo que consume habitualmente"; "Consumí mucho tiempo pasta base pero la dejé y ahora lo único que consumo es marihuana"; "Me quedé con la marihuana porque es la que pega mejor, lo único es que da mucha hambre cuando te agarra el bajón"; "La marihuana pega mejor nada, te hace sentir bien y creativo y activo"; "Prefiero el porro, es la mejor de todas las drogas, causa gracia... El porro es lo mejor de todo porque te hace comer y engordar").

El dinero para comprar estas drogas se procura por lo general mendigando a los transeúntes durante el día. El consumo diario de Poxi-ran indican oscila entre una y tres latas de cuarto o medio kilo de sustancia que se compra en la ferretería y las otras drogas a través de transas ubicados en villas o en conventillos.

El bajo costo de la marihuana incide en que resulte una de las drogas preferidas de los niños ("A los 7 probé el poxi y probé el porro a los 9,10 años. Entre uno y otro pasó un par de años... Y después por día fumaba una baaaanda porque se vendía re barata a \$1!"). Los niños que declaran haber consumido drogas perciben en sus amigos que la marihuana les produce un fuerte efecto que los desequilibra ("Los chicos que consumen porro enloquecen porque si tienen plata antes de dársela a la mamá se van a comprar más. Apenas prueban el porro se emocionan").

El Paco lo compran directamente en las cocinas y lo consumen en las inmediaciones de estos lugares ("Se compra en el conventillo frente al Parque Lezama donde está la cocina... ahí venden paco") o en lugares donde habitu- almente están los niños ("Compro en la puerta de la escuela").

Los niños pierden progresivamente el miedo al consumo de drogas dado que sienten que controlan los riesgos. Las drogas, además, rápidamente comienzan a cumplir una función de anestesia frente al dolor físico y subjetivo. Entre los efectos subjetivos más importantes, el Paco actúa como euforizante, permitiendo que los niños evadan pensamientos funestos y pierdan la sensación de miedo siempre presente por innumerables causas asociadas al desamparo de la vida en calle.

Pareciera que una de las funciones más importantes de la droga para estos niños es la alteración del sensorio y la consecuente modificación en la subjetividad que conlleva. Por ejemplo, las alteraciones cenestésicas les permiten olvidarse de sus cuerpos ya que desaparecían de su conciencia malestares y dolores.

Las drogas, además, rápidamente comienzan a cumplir una función de anestesia frente al dolor físico y subjetivo ("La marihuana me gusta porque me deja tonto, me cago de risa por cualquier cosa, me pueden estar matando que me río..."; "Con el Paco no tenía miedo de nada, no sentía nada, cuando la policía me golpeaba. Fumaba tres tarritos por día").

Cuando los niños comienzan a consumir Paco se vuelcan rápidamente a un consumo diario e intenso. Entre otros motivos, destacan que cuando pasa el efecto de la dosis consumida las sensaciones asociadas al bajón son muy desagradables ("Se me ocurrió fumar Paco porque vi a unos amigos que fumaban y entonces me re-colgué y empecé a fumar y a fumar.... Me dura poco, entonces fumo cada dos por tres porque sino me agarra mucho bajón"; "Uno se siente con una gran energía, que puede correr y no lo alcanza nadie. Me mareo pero me dan muchas ganas de caminar, cuando se me pasa el efecto tengo que fumar sí o sí porque sino empiezo a vomitar. O si no, me agarra el bajón y me quedo dormido donde sea").

Entre los efectos subjetivos más importantes, el Paco actúa como euforizante, permitiendo que los niños evadan pensamientos funestos y pierdan la sensación de miedo siempre presente por innumerables causas asociadas al desamparo de la vida en calle ("Consumo Paco y me pongo re-loco, no pienso en nada y no tengo más miedo").

En cuanto a las modalidades de consumo 
del Paco y la parafernalia que se utiliza en cada una de ellas, básicamente se puede hablar de una modalidad de consumo en cigarrillo al que llaman 'mezcladito' ("La marihuana la consumo mezclada con pasta base o sola, en cigarros armados ... se llaman 'mezcladitos'; "Pongo el Paco con un poco de faso y merca, queda todo junto y lo pongo en un papel para fumarlo"), y a través de diversos tipos de pipas construidas con papel, alambre y otros elementos como virulana, corchos, papeles metálicos, tapas de gaseosa, etc. ("El Paco es un polvito blanco, que vos lo tenés que meter en un papelito chiquitito mordido, vos lo tenés que abrir, hacer una pipa, y donde tira, fumás"; "La pasta base que es lo que más consumo, lo fumo con una pipa, cortado con virulana"; "Para fumar el Paco lo preparo yo en unos tubitos de antena. A eso le pongo virulana adentro y después lo quemo o lo mojo y me lo mando").

Por lo general los niños temen las intervenciones institucionales, tales como el hospital público y la policía, porque dicen saber que al haber delinquido son enviados a institutos de menores, instituciones que consideran de carácter carcelario ("Fui varias veces a hospitales por problemas que tuve en la calle pero siempre me llevaron a la fuerza y me escapé para que no me metan en un instituto"; "Estuve en el instituto San Martín y en Colonia Gutiérrez"; "Una vez mi mamá me cortó con un cuchillo, fui a la escuela y me llevaron de la escuela a un instituto").

Los niños más pequeños anhelan jugar y estudiar (Me gustaría andar en bicicleta. También me gustaría jugar al fútbol en un equipo contra otros equipos"; "Me gustaría tener unas zapatillas nuevas en Navidad y jueguitos de computadora, quiero tener plata para ir al cyber todo el tiempo"; "Me gustaría volver a la escuela, porque a mí me gustaba la escuela"; "Me gustaría aprender sobre todo oficios"; "Yo quiero ser abogada"; "No quiero andar más en la calle, voy a ver si puedo terminar la secundaria. Y después estudiar gastronomía. Quiero ser cheff").

Los niños de mayor edad anhelan insertarse laboralmente ("Me gustaría estudiar y después trabajar en un country como electricista"; "Quiero laburar de albañil"; "Me gustaría conseguir un trabajo, eso me tranquiliza, no me gusta estar sin trabajar"; "Ahora quiero empezar a trabajar. Con la plata voy a comprarme ropa"). Saben, además, que para poder estudiar y/o trabajar van a tener que dejar la calle ("Quiero salir de la calle, alquilar una pieza de hotel con mis amigos...podríamos pagar con lo que sacamos de los malabares y de limpiar parabrisas. Me gustaría terminar la secundaria y estudiar para maestra jardinera").

\section{UNA REFLEXIÓN A MODO DE CONCLUSIÓN}

La ciudad margina grandes grupos de población entre los cuales los niños de calle resultan un grupo en especial situación de vulnerabilidad. Se desarrollan y socializan en las calles, ajenos a los principios rectores del amparo considerado necesario para los otros niños. Son niños cuyas necesidades se invisibilizan, así como conductas adictivas y su camino hacia el deterioro psicofísico es cierto.

El consumo de drogas en estos niños resulta alarmante tanto por su cronología vertiginosa como la edad temprana en que se inicia y la toxicidad de las drogas que consumen. Se instala para desdibujar el desamparo y el miedo en la calle. La mendicidad asegura el dinero para el consumo, de modo tal que los niños aseguran la anestesia en la cotidianeidad dolorosa y plena de emociones desagradables. La ciudad, asegura por distintas vías la accesibilidad de los niños a las sustancias.

Es por esta situación de vida especialmente difícil en la que sobreviven los niños/as en situación de calle, las acciones preventivo comunitarias y asistenciales, no pueden ser las mismas que se realizan con otras poblaciones de niños/as. Teniendo en cuenta la complejidad de factores que intervienen, resulta insuficiente focalizarse solo en la abstinencia de las drogas, sino que debe incluirse el abordaje de problemáticas asociadas a su plena inserción social y su salud física y mental incluyendo desnutrición, enfermedades de transmisión sexual, de la piel, lesiones por agresiones, etc., de manera tal que se garantice el desarrollo de todas estructuras $y$ funciones que hacen a la persona.

Debe ser un compromiso de todos aquellos que trabajan con niñez desde la perspectiva psicológica, médica y social, dar respuesta en forma responsable a la urgencia de una población de niños que requiere revisar sistemas de evaluación, prevención y asistencia de las variadas problemáticas psicosociales que padecen.

A la luz de todo lo expuesto, y en función de la dimensión y características que ha adquirido el consumo de sustancias en el territorio de la 
ciudad, se considera la necesidad de adoptar un enfoque de carácter psicosocial para la comprensión del fenómeno, desarrollado en el marco de políticas públicas en prevención y asistencia de consumo de drogas, que contemplen la voz, necesidades, problemas y capacidades de los niños/as marginados en las grandes ciudades, instalando en estos grupos y en la comunidad en general, la conciencia del daño individual y social que comporta el consumo de drogas.

A sabiendas que casi ningún niño en situación de calle cuenta con una red de sostén socio familiar, ni ha alcanzado un nivel educativo suficiente para informarse, pedir ayuda y encontrar canales de expresión que les permitan no quedarse solos a merced de la compulsión al consumo de drogas y la pobreza, las acciones asistenciales (oferta servicios de internados y casas hogar), deberían seguir un modelo comunitario de trabajo que comience en la calle, donde niños/as sean actores incluidos en las redes sociales en un proceso de interacción constante y cotidiana.

Esta investigación se ha de complementar con estudios futuros que aporten datos para consolidar un cambio en las actitudes y representaciones sociales sobre la infancia y la juventud en situación de vulnerabilidad social, superando prejuicios que dificultan la construcción de un nuevo clima social favorable a la infancia, y la adolescencia.

\section{REFERENCIAS}

Aries, P. (1988). El niño y la vida familiar en el antiguo régimen. Tauros: Madrid.

Boqué Miró, R. (1994). Los chicos de la calle. Advocatus: Buenos Aires.

Brasesco M.V, Legisa A. (2009). Consumo de Paco y sustancias psicoactivas en niños y niñas en situación de calle y jóvenes en tratamiento, Gobierno de la Ciudad Autónoma de Buenos Aires.

Giberti E. (comp.) (1997) "Políticas y niñez". Buenos Aires: Losada.

Grima, J. M.; Le Fur, A. (1999), ¿Chicos de la calle o trabajo chico?, Lumen Humanitas: Buenos Aires.

Kokoreff, M. (2006). Pratiques urbaines d'un quartier de gares. Spaces et Societé, 108.

Lucchini, R. (1996) Niño de la calle. Identidad, Sociabilidad, Droga. Barcelona: Los Libros de la Frontera.

Mazzini, P. (1996) “Niños/as y jóvenes en situación de calle. Espacio y campo social". Institut Universitaire d'éstudes du Développement. Université Geneve.

Miguez, D. (2002) "Rostros del desorden. Fragmentación social y la nueva cultura delictiva en sectores juveniles", en Gayol, S. \& Kessler, G., "Violencias, delitos y justicias en la Argentina". Buenos Aires: Manantial.

Miguez, H. \& Grimson, W. (2002), "Los vidrios oscuros de la droga". Buenos Aires: Universidad Nacional de Quilmes. Moffat, A. (1991) "Los chicos de la calle: el psiquismo acrónico", Psicología Social Hoy, marzo/abril.

Valles, Miguel (1997) “Técnicas Cualitativas en Investigación Social". Síntesis: Madrid.

Taylor, S. \& Bogdan, R. (1998), "Introducción a los Métodos Cualitativos. La Búsqueda de Significados". Paidós: Barcelona.

Para citar este artículo:

Brasesco, M. V., (2011). Niños de la calle: Buenos Aires SXXI. Ciencias Psicológicas V (1): 7-18. 